\title{
Exploring Impacts of IT in Language Teaching in China $^{*}$
}

\author{
Changlin Sun \\ Shandong Jianzhu University, Jinan, China
}

\begin{abstract}
As an effective assistant tool of instruction, information technologies are being accepted and applied to the classroom education. The use of computers, Internet, and email etc. is changing the literacy practice, student identities and pedagogy. However, different attitudes towards information technologies emerge as well. How to critically analyze the influence of information technology on language teaching, literacy practice, student identities, and pedagogy, and how to apply this technology to language teaching in China are what this paper aims to.
\end{abstract}

Index Terms - IT, identity, multiliteracies, pedagogy, critical thinking, language teaching

\section{INTRODUCTION}

It is widely acknowledged that one of the most significant changes in the globalization process has been the emergence of information and communication technology. The fastest growing of information and communication tool, the computer devices, the Internet, has enabled people from different fields, areas and cultures to communicate rapidly and to access information quickly. Nowadays, as an effective assistant tool of instruction, information technologies are being accepted and applied to the classroom education step by step.

As schools are increasingly wired to new information technologies, the space of learning is no longer confined to that of the physical space of the classroom. Schools therefore require new ways of teaching and learning. The use of computers, Internet, and Email etc. changes the literacy practice, student identities and pedagogy. A set of new skills concerned with social, cultural and pedagogical implications in the classroom need to be taken into account. The traditional teaching and learning method will no longer suffice.

However, different attitudes towards information technologies emerge as well. Worrying about taking risk by using computers for teaching and learning or unwilling to pay for buying new technological facilities, IT is resisted by some schools and teachers. Furthermore, under the pressure that promoting using of computers means some teachers will not be employed any more, schools are unwillingly to use computers as well. In this paper, I will critically analyze issues about IT in school education, and demonstrate how it is applied into schools' teaching in China.

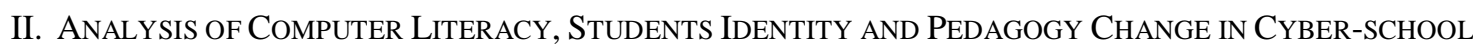

When traditional classrooms are challenged by wire-based classroom; when face-to-face teaching confront with long distance computer teaching; when students talk with code language and immerge themselves in a virtual world, people deeply recognize the coming of "Information Age". The widely use of computers and Internet takes education into globalization as well. Luck (as cited in Luke C., 1996a) states:

The shift from print and paper to electronic textuality, the proliferation of information resources and databases, global knowledge and social networks, require very different multimodal and multimedia - social and literacy skills from those conceptualized on the basis of an essentially assembly-line, factory model of schooling, and static linearity of print - and book-based models of literacy.

\section{The necessity of developing computer literacy skills}

Luke's issue on the development of computer literacy skill is important. When paper-based reading and writing cannot satisfy the requirement of using computer, new skills need to be explored. What is computer literacy? Adams (1984, p.49) gives an explanation as a general understanding of uses, advantages and limitations of computers. Eisle (1980, p115) states from a more specific aspect that developing computer literacy skills means to develop skills which enable oneself uses computer applications to influence a whole life situations such as commutations, education, entertainments etc. For instance, online language learning has become a more and more significant learning style in school education compared with traditional language learning style. Online language learning relies on e-libraries, computer database to a large extent. With computer literacy, one is easy to access to e-libraries and professional database which provide amounts of computer cataloging and information to search for and to download. With the help of information technology, language learning efficiency has been improved enormously. However, if one is

\footnotetext{
* This paper is one of the achievements of programs of Shandong Soft Science Study Program (2012RKB01185) and Shandong Education Bureau Program (J12WE01).
} 
incompetent for computer literacy, he or she will not conduct online learning successfully. Here computer literacy is a key element to gaining useful access to computerized services, as well as understanding and reshaping the world.

Furthermore, Luke (2000, p.69) in her article notes blended vocabulary and reading-writing practices require new multimodal and multimedia literacy and laterally connected features of electronic texts. Giving that reading and writing words is the basic form of literacy, then computer literacy consists of the ability to use computer to store information, retrieve information and manipulate information, which seems like the world opens a knowledgeable window in front of man. On the other hand, a critical thinking about the computer literacy should not be neglected although it enables people to combine the particular medium with reading, writing and the creation and transmission of information. As was noted by Douglas Noble (1984, p.37), computer literacy is important but not necessary in most people's daily life, it only supplies another way of recognizing the world.

From a critical perspective, although developing computer literacy practices can broaden student's view of the world and is seen as activities of creating system to get information and achieve academic goals, it still has weaknesses in three aspects:

First, students' spelling level gets weaker than before with much of practices using computer to read and write. Whenever spelling mistake appears, Word Processor will remind the mistake automatically. What a student needs to do is just press the button slightly and the correct spelling immediately appears. How convenient it is. Students do not need to care about spelling any more. As a result, their spelling level decreases.

Next, it is difficult for computer literacy to deliver beautiful and imaginative information in language and literature teaching as the traditional teaching does. For instance, using computer to teach Chinese Ancient Language Literature, the poems are usually translated by their literal meaning, but the metaphorical meanings are difficult to be expressed, therefore, the real contextual literature imagination is limited. In addition, computer literacy in most circumstances stays at a "silent" position to teach reading and writing, it cannot deliver any emotional information from teacher's tune, face and posture. It seems too "Cool" compared with the traditional literature teaching aims to elicit students' imagination.

Last, once students have the ability to use computer to read and write, they may also get some ill contents like pornography, bloody and violence; or they may indulge in computer games. Consequently, they are affected seriously and it may become the potential inducement of social problems such as crime, prostitution etc.

2. Exploring Personal Identity in Cyber-Schooling

In the real world, no matter a person is rich or poor, healthy or sick, every one owns the personal identity, which is authentic and recognized by family, community and the society. However, in digital hyperspace, bodily differences are invisible and irrelevant. Bollier (1994) holds the similar opinion that one of the most intriguing and emotionally intense virtual communities are the strange new environments that allow diverse computer users from around the globe to carry on focused conversations in "virtual rooms". Again Luke (2000) states that in the hypermedia realm of pure information where we construct ourselves primarily though text - distinctions of gender, ethnicity, body shape or impairment, accent or speech styles don't matter. We know from decades of research that the student with an accent or wearing a turban, the one with the lisp, the overweight or the indigenous students, is often treated differently from the mainstream ideal student by teachers and peers. But in virtual communities, where one's social identity is wholly textually constructed, such differences vanish, which means that traditional categories of the social subject and social differentiation may no longer be useful.

Take a Chinese classroom as an example, in a traditional Chinese classroom, students' identity is simple, they are learner and are required to take knowledge from their teacher. Actually, not everyone does well. Because some students who are not active are unwilling to ask questions even they do not understand. They worry about if their questions are stupid or if they will be laughed at by peers. In this face-to-face environment, everybody knows who you are, what you behave is under the eyes of others. However, in virtual spaces, this situation is changed. Students do not worry about "lose face", or if they do not like, they can just change a new name. In the virtual world, one person can have different identities. He or she can be a student, a teacher, a professor or whoever they want. They can say whatever they want to say, because their identities are not real identities, they have no worries about "right or wrong", "good or bad". Even if somebody claims he is Bill Gates, nobody will probe who he is at all. Hence, the virtual spaces provide possibilities for people to explore their personal identities. It provides students opportunities to change identities not only for academic purposes but for fun as well. Through virtual spaces, students are creating virtual bodies, characteristics. Paradoxically, according to Bollier (1994), a lot of what these virtual spaces allow is to escape from dealing with disembodied voices, because now a person has a virtual body, accent and personality you can recognize.

With the new identity or new role in the cyberspaces, students may learn how to take more responsibilities than in the material spaces. The reason is in the real world, they may be shy, not confident enough, or not competitive, they are seldom given chances to manage a class or organize activities. But in a virtual community, those non-active students could be very creative and critical; they could be motivated by critical thinking, by joining discussion actively. Their identity could be web master or organizer, involuntary they take responsibility for organizing discussion, answering questions, solving problems and updating information. By doing these, not only students' confidence is improved, but also their personalities and responsibilities are enhanced.

Although in cyber-sociality, there is lack of embodied and gestural cues coupled with face-to-face communication, people may be impossible to realize the real situation or know about the people whom we are chatting with online, it 
could be argued that in the cyber spaces, identity still could be discerned by subject's practical activities. Here practical activities mean people's attitudes, thoughts, and opinions towards specific issues by chatting, emailing or discussing with others. But this identity judgment is an invisible judgment. Though it cannot supply any direct and first eye information, or sometimes it may leads to misjudgment, it does supply a comprehensive and critical recognition process towards people's real identity. This process is like a charcoal drawing, the painter draws the rough picture first and then keeps on modifying in order to get the most lifelike painting. Likewise, once recognition is formulated by continuous affirmation and denial, it may very close to a person's real characters.

3. Reflecting pedagogy changes in cyber-school

Rather than having threatening implications for teachers' work, learning and teaching in cyberspace can in a large degree help teachers download the tremendous pressure from their shoulders and to explore all their potential and ability to facilitate students' learning in classroom. Once teachers are no longer busy with the "batch processing of students through a mass-market basic curriculum", they will truly become an instructor, facilitator, or helper to students. Likewise, Loveless (1995) also claims that constructing knowledge from information requires an ability to question, access, interpret, amend, analyze, construct and communicate meaning from information. It is not hardly to see that such abilities are challenging teachers' teaching philosophy and setting up a higher standard for them. Only if teachers know cyber-school learning situation and know when and how to use digital technologies appropriately, then cyberschool education would be really successful. For example, in the networked courses, teachers need to enhance cooperation in order to develop and share pedagogical practice (Loveless \& Ellis, 2001). The standards - such as maintaining a purposeful working atmosphere, effective questioning, careful listening and providing students with opportunities to consolidate knowledge do not change substantially with the integration of IT (DfEE, 1998). The lessons and activities still need a clear purpose, structure and pace, and to elicit participation.

For example, a study of pedagogy using IT for literacy and numeracy in an English primary school highlighted patterns in the links between teachers' approach to teaching, some aspects of their characteristics and their observable behaviors in the classroom. And who were more positive about the use of IT in their teaching tended to have welldeveloped IT skills themselves and to value pupils' collaborative working, inquiry and decision-making. Teachers who expressed reservations about using IT were more likely to be highly directive and to organize students' individual work in the classroom (Mosely et al., 1999). If most teachers reflect the fundamental characteristics of information technology by testing their current teaching practice and beliefs, teacher education and professional development face complex challenges in approaching the changes required to meet the demands of teaching in the "Information Age", where technologies act as a catalyst for radical educational change and in which " locating, collating and summarizing information and identifying connections and contradictions within a body of information all need to be explicitly moved to the center of the classroom (Scrimshaw, 1997, p.100).

What is teachers' role in computer-based pedagogical environment? It is supposed by Loveless \& Ellis (2001):

- A collaborative teaching and learning controller - employing the technologies to increase connective between information, teachers and learners and assist in overcoming restrictions of location and timetable.

- A powerful director - making use of the technology to support teaching by including high-quality texts, images and sound to structure, illustrate and represent ideas in formal lecture instruction.

- A facilitator - using the technology to improve the students' quality of life in their learning experiences on part time and distance - education courses, by ensuring interactive communication between the course leaders, teachers and learners and building up an ethos appropriate to a learning community.

- A designer - good at producing high-quality interactive learning materials to help students participate in the subjective content and demonstrate the ways in which they had made connections and constructed their own understanding of the world.

Spontaneously, it will be linked that how students' role is changed in cyber schooling? From the research of Simpson and her colleges (1998, p101), students' attitude towards IT exhibited very positive. They enjoy using computers, Internet and feel it important to learn how to use them. By using IT, students develop group learning and collaborative problem-solving skills. Luke (2000) holds the same opinion that students in cyber-classrooms prefer working together to acquire information and skills by surfing on websites and databases. The ability to input, download, drop and drag material and imagery from global library of information creates new skills, processes and multimodal forms of production that encourage interdisciplinarity, creativity and imagination, collaborative authorship, editing, reading and writing, and problem-based learning. Sometimes the collaborating work could be peer tutoring, after that it could be shifted to literature-based activities. Students are encouraged to develop emailing project and motivated to write, they are willing to exchange personal experiences, hobbies and interests by attaching a digital photograph of themselves. Even they use email to link up internationally to know about different cultures and make different friends. Furthermore, students are encouraged to design pages for the school web site. This work promotes students to search for various background knowledge such as culture, history, geography and so on. They often grouped together and work collaborated. They share their work with others through Intranet facility and therefore their collaboration work is enhanced.

However, when many people affirm the positive effects of IT to pedagogy changes, different voices are heard as well. The opposite opinions stay that teachers should play the role of instructor, demonstrator, project manager, consultant, 
resource provider, questioner, explicator, observer, model learner and co-learner. They know how to intervene to encourage students autonomy; they know when to stand back to allow children time to work through uncertainty to solutions; they know when to ask a question to challenge or divert, know how to balance guidance. These are intelligent action which lies at the heart of effective teaching skills, and which reflective teachers develop throughout their teaching careers (Loveless, 1995). They suspect teachers' instruction will get weaker and weaker, their no confidence or no experience on IT will make their students take risk. At the same time, students' new roles in cyber-based schooling are also doubted. For example, peer tutoring is thought a collaborative interaction between students. However, it may lead to waste the more able students' time. In addition, the more proficient students use computers, they may possibly become addicted to them.

\section{CRitical Thinking ABOUt Information TeChNOLOGY}

Just like every coin has two sides, when the positive side of Information Technology is acknowledged, the negative side appears simultaneously. The negative side of "labor saving and increased leisure time" can be unemployment, which in turn proves the fact that the introduction of new technology has both eliminated and created jobs (Bernard, 1991). Some scholars like Luke points out in 2000 that not all groups welcome the advent of the new technologies and, as a result, many will be disadvantaged in an increasingly competitive labor market where computer related techniques and skills are considered particularly important. IT does create new job vacancies, however, those job need more professional people to fill in. People are required not only be proficient in operating computers, mastery technological literacy, but also possess professional knowledge and with higher creative and innovative ability. It is a trend that technology-dense job will take the place of labor-dense job, more and more labors will struggle for less and less labordense positions. As a result, the competition in low level of technology market becomes seriously. Far more people will encounter with the risk of losing job. On the other hand, those who work with technology systems will complain that they have no control over their work, that machines now govern their daily pace. Bernard (1991) says as more and more work becomes machine-regulated, people may increasingly become alienated from their jobs, coworkers, clients and customers. According to Levin \& Rumberger (1983) new technology demands for higher skills than before, a usual prescription is that there must be a vast transformation of the educational system. Schools are expected to adapt new responsibilities through major curricula as well as teacher preparation. In consequence, elementary and secondary schools are supposed to improve virtually all their instructions which demands analytic and communicative skills.

\section{How Are School Classrooms in China AfFected by New TeChNOLOGY}

With IT is introduced into education system, schools are facing the challenge bringing by new technologies. In china, with the appearance of the computer and the Internet, many schools have set up the broadband network, therefore, among different schools, it is quite convenient and fast to share various outcome of teaching or teaching software designed by excellent and distinguished educators via the net; teachers can also download curricular information from the web to use with their classes so as to introduce students more up-to-date knowledge outside the text book. To the students, they are challenged to develop computer-based literacy as soon as possible. Students are facing the new subject how to use keyboard to input and output information; how to search for information on the web; how to verify different audio and/or video symbols, and how to use email to communicate with others, to join in discuss activities. For example, in order to improve students' computer literacy, a classroom teacher can ask students to search for related material from Internet about a specific topic and ask them to write a reflective journal, diary or short essay then email this writing to the teacher. By doing like these, the comprehensive ability of using computer and Internet for searching for information, reading articles, checking spelling, organizing writing structure and receiving or sending emails is enhanced. In addition, the teacher can give feedback quickly by E-ways. In contrast, the traditional way of checking up writing paper wastes teacher so much time that students have to wait a long time to know the results. Using the net makes feedback between teacher and student much easier. With the help of the net, students can check up their achievements automatically, meanwhile, by analyzing the information about an individual student's progress (Van, C.E., 2003, p.273).

Secondly, Internet-based instruction changes the traditional teacher-centered learning into the student-centered learning, which to a large extent improves the child's motivation to learn. In the circumstance of traditional mode of education, without any choice, students have to acquire knowledge passively. In the internet-based class, students can study actively according to their own interests and competence. In addition, associating the advanced technology of digital media, students are more likely to exert their potential creativity, and engage in critical thinking. In such an electronic social environment, teachers need to be aware of what students' interest is, what abilities they have mastered and which skills they need to improve. Associating with the features of young adolescents and the new requirement to education in the new times, teachers play a vital importance role in guiding students to use modern technology to improve their learning efficiency. The traditional "give" and "take" way will not work well, the new model of teaching and learning is based on discovery and participation. In this process, teachers are key players in guiding students to exert their acquired cognitive structure and to further develop their potential capabilities. Students will not effectively participate in the activities or fully utilize their currently mastered knowledge unless they are interested in the topic. 
Thirdly, it is necessary to emphasize the interaction between teachers and students. Chinese young adolescents prefer to keep silence and are less active than their peers in western countries, who have strong individuality and are willing to show their capacities in public. Partly because Chinese traditional culture advocates introversion, however, to a large extent, long-term teacher-centered learning results in Chinese middle years uncreative and non-confident. Chinese students seem adapted to receiving knowledge passively, and preferred to write down whatever teacher says rather than ask why. Some students even feel nervous and frightened to answer questions in class. In the environment of digital media, according to their individual level of cognition, students can independently and flexibly control the whole process of learning with teacher's advisable instruction. Teacher, who now acts as participant but not a dictator, may ask students to read on the Internet, make comments, discuss and learn from each other. In the words of Tapscott, (1998 p. 141) "Various digital forums...enable brainstorming, debate, the influencing of each other-in other words, social learning." Teachers can also use E-mail, chat sessions, bulletin-board-type forums, and shared digital workspaces to create opportunities for communication between individuals, pairs, and groups. As Tapscott, (1998) argues that in a new environment of learning, which is created by the new media, the learner is able to interact and connect with others. At this point, what teachers should do is not transmit knowledge up to down but guide students to communicate, take part in their discussion and give some essential instruction so as to truly realize the interaction between teacher and students.

\section{CONCLUSION}

In the new environment of information technology, teachers and schools do have to consider combining technologies, new communities, globalization together and to frame their response appropriately with effective pedagogies, literacy and new identities. Under the condition of the Internet, singular cultural and linguistic messages have no longer stimulated students' interests, which have been impacted by mass media culture and global networks. With the advanced information technology into class, students are effectively applying the knowledge learning in school to their real lives. Although, exploring internet-based instruction has not achieved a satisfying progress in China, with the development of science and technology, and the promotion of education reform, it is certain that internet-based instruction will exert its advantages and serve the modern education further.

\section{REFERENCES}

[1] Adams, James A. (1984). Networked computers promote literacy and computer-Assisted instruction. T.E. Journal, May, 1984, 44-53.

[2] Bernard, E., (1991). Technological Change and Skills Development. Melbourne: Deakin University Printery.

[3] Bollier, D. (1994). The Future of Community and Personal Identity in the Coming Electronic Culture. Washington, DC: Aspen Institute.

[4] Burbules, N. \& Callister, T. (2000). Watch It: The risky promises and promising risks of new information technologies for education. Washington, DC: Western View Press.

[5] DfEE. (1998). Initial Teacher Training National Curriculum for the Use of Information and Communications Technology in Subject Teaching, Circular. London: Department for Education and Employment.

[6] Eisle, James E. (1980). A case for universal computer literacy. Journal of Research and development in education. V.14, No. 1, 1980, 111-120

[7] Jones B. (1991). Computer and literacy. San Diego: University of California Press.

[8] Levin, H. \& Rumberger, R., (1983). Educational Implications of High Technology. Paulo Aoto, Calif: Institute for Research on Educational Finance and Governance, Stanford University.

[9] Loveless, A. (1995). The Role of IT: Practical Issues for Primary Teacher, London: Cassell House.

[10] Loveless, A. \& Ellis, V. (2001). ICT, Pedagogy and the Curriculum: Subject to Change. London and New York: Routledge Falmer.

[11] Luke, C. (2000). Cyber-scholing and Technological Change. In B. Cope \& M. Kalantzis (Eds), Multiliteracies: Literacy Learning and the Design of Social Futures. Sydney: Macmillan, 69-91.

[12] Mosely, D., Higgins, S., Bramald, R., Hardman, F., Miller, J., Mroz, M., Tse, H., Newton, D., Thompson, I., Williamson, J., Halligan, J., Bramald, S., Newton, L., Tymms, P., Henderson, B. and Stout, J. (1999). Ways Forward with ICT: Effective Pedagogy Using Information and Communications Technology for Literacy and Numeracy in Primary Schools. Newcastle: University of Newcastle.

[13] Noble, D. (1984). The underside of computer literacy. Raritan, Spring 1984, 37-64.

[14] Scrimshaw, P. (1997). Computer and the teacher's role. In B. Somekh and N. Davis (eds), Using Information Technology Effectively in Teaching and Learning. London: Routledge Falmer, 100-103.

[15] Simpson, M., Payne. F., Munro R., \& Lynch, E. (1998). Using Information and Communications Technology as a Pedagogical Tool: a survey of initial teacher education in Scotland. Journal of Information for Teacher Education, Vol. 7 No. 3, 1998, 95107.

[16] Van Kraayenoord, C.E. (2003). Literacy assessment. In G. Bull \& M. Anstey (Eds.), The literacy lexicon (2nd ed.). French Forest, NSW: Prentice Hall, 273-287.

[17] Tapscott, D., (1998). N-Gen learning. In D. Tapscott, Growing up digital, Ch 7. New York: McGraw-Hill, 125-157 
Changlin Sun was born in Jinan, China in 1970. She received her Master's degree in educational study from The University of Queensland, Australia in 2005.

She is currently a lecturer in the School of Foreign Languages of Shandong Jianzhu University in Jinan. Her research interests include TESOL, cross-cultural comparative study, and American literature. 